\title{
Tipik Bir Çelik Endüstri Yapısında Çaprazlı Perde Tipinin Deprem Performansına Etkisi
}

\author{
Kaan TÜRKER ${ }^{* 1}$, İbrahim LEKESiZ ${ }^{2}$ \\ ${ }^{1}$ Balıkesir Üniversitesi, Mühendislik Fak., İnşaat Müh. Böl., 10050, Balıkesir \\ ${ }^{2}$ Net İnşaat, 10100, Balıkesir
}

(Alınış / Received: 09.12.2016, Kabul / Accepted: 05.09.2017, Online Yayınlanma / Published Online: 20.09.2017)

Anahtar Kelimeler Özet: Çalışmada, Türk Deprem Yönetmeliği 2007’ye göre Çelik endüstri yapısı, tasarlanan çelik endüstri yapılarında farklı çaprazlı perde Deprem performansı, alternatiflerinin deprem performanslarının değerlendirilmesi Merkezi çaprazlı amaçlanmıştır. Çalışmada 4 farklı merkezi çaprazlı perde tipi perde sistem, Doğrusal olmayan statik yöntem (diyagonal tip, ters- $\mathrm{V}_{\text {, }} \mathrm{X}$, ve iki katta-X) incelenmiștir. Her bir çaprazlı perde tipi süneklik düzeyi normal ve yüksek olarak ayrı ayrı tasarlanmıștır. Ayrıca yüksek narinlikte elemanların kullanıldığı sadece çekmeye çalışan X tipi çaprazlı perde de incelenmiştir. Performans değerlendirmelerinde ASCE/SEI 41kriterleri kullanılmıștır. Diyagonal tip, 2 katta X tipi ve sadece çekmeye çalışan $X$ tipi sistemlerde daha iyi deprem performansları elde edilmiştir. En düşük performans seviyesi ise ters-V tipi çaprazlı sistemde elde edilmiștir.

\section{The Effect of Bracing Type on Seismic Performance of A Typical Industrial Steel Structure}

\begin{abstract}
Keywords
Steel industrial

structure,

Seismic performance, Concentric bracing

system,

Non-linear static analysis

Abstract: The purpose of the study is to evaluate the seismic performance of bracing alternatives in steel industrial structures designed 2007 Turkish Earthquake Code. Four types of concentric bracing systems (inverted-V bracing, $\mathrm{X}$ bracing and two-story $\mathrm{X}$ bracing) were evaluated in the study. Each bracing system was designed for normal and high ductility levels. Tension-only $\mathrm{X}$ bracing including very slender elements were also investigated. ASCE/SEI 41-13 criterias were used in the performance evaluations. Better seismic performance levels were obtained with diagonal bracing, two-story $\mathrm{X}$ bracing and tension-only $\mathrm{X}$ bracing systems. Least performance level was obtained from inverted-V bracing system.
\end{abstract}




\section{Giriş}

Dayanım ve elastisite modülünün diğer malzemelere göre çok yüksek olması, inşa süresinin hızlı olması v.b. sebeplerle yapı malzemesi olarak çeliğin inşaat sektöründeki kullanımı hızla yaygınlaşmaktadır. Bir çok yapı türünde kullanılmakla beraber ülkemizdeki çelik yapıların yaklaşı \% 60'ını endüstriyel çelik yapılar oluşturmaktadır. Endüstriyel yapıların da büyük bir kısmını atölye ve fabrika amacıyla kullanılan tek katlı veya birkaç katlı yapılar oluşturmaktadır [1]. Bu tip yapıların taşıyıcı sistemleri, genellikle bir doğrultuda eğik çatılı portal çerçeve sistemlerden veya ankastre kolonlara oturan kafes kirişli sistemlerden, diğer doğrultuda ise çaprazlı perde sistemlerden teşkil edilmektedir (Şekil 1). Ayrıca çatı düzleminde aşıklar ve stabilite bağlantıları teşkil edilerek sistemin bütünlüğü sağlanmaktadır $[2$, 3].

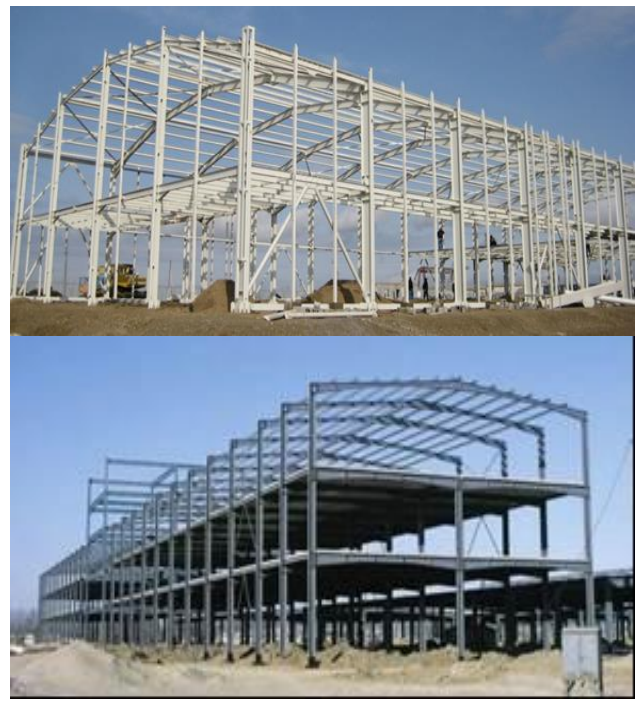

Şekil 1. Tipik arakatlı endüstri yapısı örnekleri

Endüstri yapıları, Deprem Yönetmeliklerinde genellikle önem katsayısı en düşük yapılar arasında yer almaktadır. $\mathrm{Bu}$ nedenle tasarımda öngörülen deprem etkisinde yapılarda önemli hasarlar oluşmaktadır. Bazı durumlarda depremde meydana gelen hasarlar, endüstri yapısında bulunan ekipmanlara verdiği zararlar ve/veya hasarların sebep olduğu üretim aksamaları nedeniyle yapı sisteminin maliyetini büyük ölçüde aşan kayıplara yol açabilmektedir. $\mathrm{Bu}$ bağlamda deprem performansı esaslı değerlendirme ve tasarım yaklașımı bu tür yapılarda önem kazanmaktadır. Bu yaklaşımda yapıların belirli bir deprem tehlike seviyesi için hasar dağılımına bağlı olarak güvenliği belirlenebilmekte veya istenilen deprem tehlike seviyesi için istenilen hasar düzeyine sahip yapılar tasarlanabilmektedir $[4,5,6]$.

Ülkemizde 2007 yılında yürürlüğe giren Deprem Yönetmeliğinde performans esaslı değerlendirme yaklaşımına yer verilmiş ancak sadece betonarme yapıları kapsamıştır [7]. 2008 yılında İstanbul'daki yüksek binalar için performans esaslı tasarımı da içeren bir deprem yönetmeliği hazırlanmıştır [8]. Bu yönetmelikte betonarme binalar için ayrıntılı olarak şekildeğiştirme esashı tasarım yaklaşımlarına yer verilmiş, çelik yapılar için ise ABD'de "Binaların Sismik Performansının Değerlendirilmesi ve Güçlendirilmesi" amacıyla hazırlanan ASCE/SEI 41-06 [9] standardının kullanılması öngörülmüştür. Çelik, betonarme ve yığma yapılar için çok kapsamlı performans değerlendirme yöntemleri içeren bu standart geliştirilerek 2013 yılında ASCE/SEI 41-13 [10] adıyla yayınlanmıştır. Aynı zamanda Avrupa'da da performans esaslı yaklaşımlar Eurocode-8 [11]'de yer almış, ancak şekildeğiştirme esaslı yöntemler betonarme yapılarla kısıtlı kalmıştır. 2016 yılı sonunda yürürlüğe girmesi planlanan yeni Türkiye Bina Deprem Yönetmeliğinde [12] de çelik yapılar için performans esaslı yaklaşımlara yer verilmiş ve bu yönetmelikte büyük ölçüde ASCE/SEI 41-13 standardı benimsenmiștir. 
Yönetmeliklerdeki kapsamı hızla genişleyen performans esaslı yaklaşımlar, ülkemizde daha çok mevcut betonarme yapıların deprem güvenliklerinin belirlenmesi ve güçlendirme tasarımında kullanılmaktadır. Özellikle çerçeve sistemlerden çok farklı deprem davranışı gösteren çelik çaprazlı perde sistemlerin performansa dayalı değerlendirilmesi önem arz etmektedir. Bu sistemlerde çok farklı çapraz tipleri ve konfigürasyonlar uygulanabilmekte, bunlar da yapının deprem performansını etkilemektedir $[13,14$, 15, 16]. Bu konuda yapılan çalışmalar kısıtlı olup genel olarak çok katlı binaları içermektedir. $\mathrm{Bu}$ çalışmada, az katlı tipik endüstri yapılarında farklı çaprazlı perde tiplerinin deprem performansına etkileri araştırılmıştır.

\section{Yapı Örnekleri Üzerinde Sayısal İncelemeler}

Çalışmada, yaygın olarak kullanılan endüstri yapılarını temsil etmek amacıyla, iki katlı, kırık çatılı hal tipi yapı formu seçilmiștir. Yapıların bir doğrultudaki taşıyıcı sistemi çerçevelerden, diğer doğrultudaki taşıyıcı sistemi çaprazlı perdelerden oluşturulmuştur (Şekil 2).

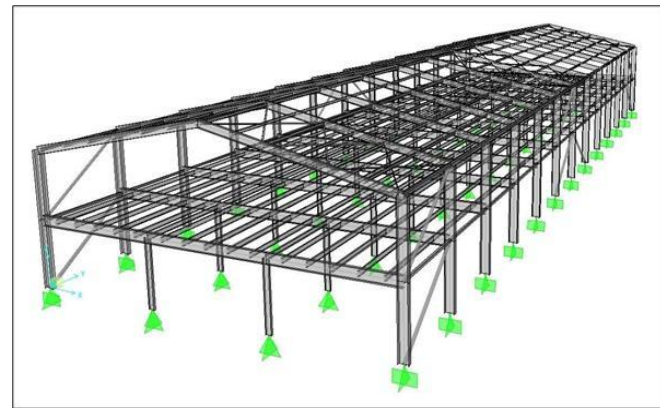

(a)

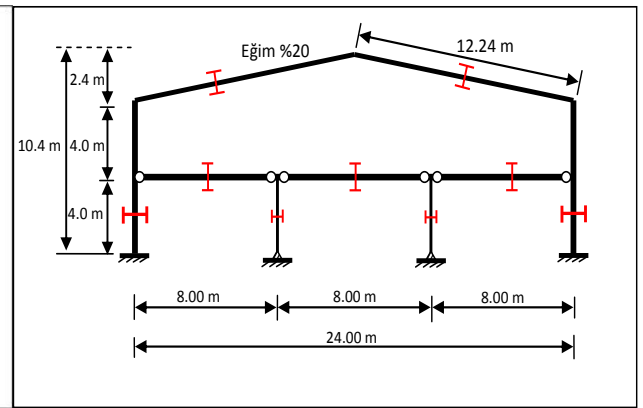

(b)

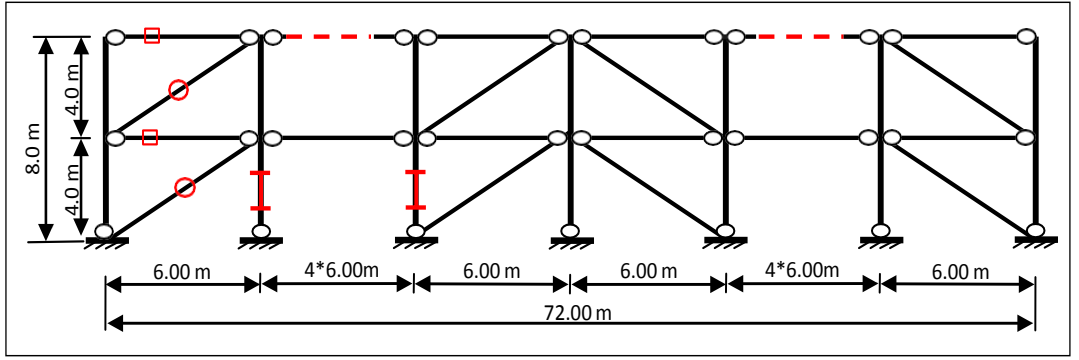

(c)

Şekil 2. (a) Sistemin perspektif görünümü, (b) Kısa doğrultudaki tipik çerçeve taşıyıcı sistem, (c) Uzun doğrultudaki tipik çaprazlı perde taşıyıcı sistem (Çapraz tipi yapıya göre değişmektedir)

Kısa doğrultudaki çatı kirişleri çatı düzleminde aşıklar ve stabilite bağlantıları ile birbirine bağlanmıștır. Kısa ve uzun doğrultuda uç bağlantıları mafsallı olan kirişler ve kolonlar kullanılarak bir arakat taşıyıcısı oluşturulmuştur (Şekil 2). Yapıların çatısında ve yan cephelerinde hafif kaplama malzemesi kullanılması öngörülmüştür. Yapının perspektif görünümü, kısa ve uzun doğrultudaki taşıyıcı sistemlerin geometrik özellikleri Şekil 2'de verilmiştir. Yapıların uzun doğrultusu 12 açılıktan, kısa doğrultusu alt katta 3 açlklıktan, üst 
katta tek açıklıktan oluşmaktadır (Şekil 2).

Çalışmada farklı alternatiflerin yapıların deprem performansina etkisini belirlemek amacıyla dört çaprazlı perde tipi incelenmiştir. Bunlar Diyagonal tipi, $\mathrm{X}$ tipi, Ters $\mathrm{V}$ tipi ve 2 Katta $\mathrm{X}$ tipi çaprazlı perdelerdir. Her bir çapraz tipi için, süneklik düzeyi yüksek ve normal sistem alternatifleri incelenmiştir. X tipi çaprazlı perdede, basınca çalışan çaprazlı alternatifin yanısıra, en çok iki katlı yapılarda kullanılabilen süneklik düzeyi normal sadece çekmeye çalışan çaprazlı perde alternatifi de incelenmiştir [7]. Çalışmada incelenen çaprazlı perde alternatifleri ve uygulama șekilleri Tablo 1'de gösterilmiştir.

Tablo 1. Çalışmada incelenen çaprazlı perde tipleri ve uygulama şekilleri

\begin{tabular}{|c|c|c|c|}
\hline Yapı Adı & $\begin{array}{c}\text { Çaprazlı } \\
\text { Perde Tipi }\end{array}$ & Uygulama Şekli & $\begin{array}{c}\text { Süneklik } \\
\text { düzeyi }\end{array}$ \\
\hline $\begin{array}{l}\text { Yap1-1 } \\
\text { (DÇ-SDY) }\end{array}$ & \multirow{2}{*}{$\begin{array}{l}\text { Merkezi } \\
\text { Diyagonal Tipi } \\
\text { Çapraz Perde }\end{array}$} & & Yüksek \\
\hline $\begin{array}{l}\text { Yapı-2 } \\
\text { (DÇ-SDN) }\end{array}$ & & & Normal \\
\hline $\begin{array}{l}\text { Yap1-3 } \\
\text { (TVÇ-SDY) }\end{array}$ & \multirow{2}{*}{$\begin{array}{l}\text { Merkezi Ters } \\
\text { V Tipi Çapraz } \\
\text { Perde }\end{array}$} & & Yüksek \\
\hline $\begin{array}{l}\text { Yap1-4 } \\
\text { (TVÇ-SDN) }\end{array}$ & & & Normal \\
\hline $\begin{array}{l}\text { Yap1-5 } \\
(2 \mathrm{KXÇ-SDY)}\end{array}$ & \multirow{2}{*}{$\begin{array}{l}\text { İki Kat X Tipi } \\
\text { Çapraz Perde }\end{array}$} & & Yüksek \\
\hline 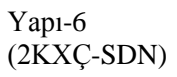 & & & Normal \\
\hline $\begin{array}{l}\text { Yapı- } 7 \\
\text { (XÇ-SDY) }\end{array}$ & \multirow{2}{*}{$\begin{array}{l}\text { Merkezi X } \\
\text { Tipi Çaprazlı } \\
\text { Perde }\end{array}$} & & Yüksek \\
\hline $\begin{array}{l}\text { Yap1- } 8 \\
\text { (XC-SDN) }\end{array}$ & & & Normal \\
\hline $\begin{array}{l}\text { Yapı- } 9 \\
\text { (ÇÇÇ-SDN) }\end{array}$ & $\begin{array}{c}\text { Merkezi X } \\
\text { Tipi Sadece } \\
\text { Çekmeye } \\
\text { Çalışan } \\
\text { Çaprazlı Perde }\end{array}$ & & Normal \\
\hline \multicolumn{4}{|c|}{$\begin{array}{l}\text { DÇ : Diyagonal Çapraz, TVÇ : Ters V Çapraz, 2KXÇ : } 2 \text { Katta X Çapraz, XÇ : X Çapraz, } \\
\text { ÇÇ : Çekmeye Çalışan Çapraz } \\
\text { SDN : Süneklik Düzeyi Normal, SDY : Süneklik Düzeyi Yüksek }\end{array}$} \\
\hline
\end{tabular}

\subsection{Yapıların tasarımı}

Yapıların tasarımı TS 648 [17], TS 498 [18] standartları ve 2007 Türkiye Deprem Yönetmeliğine [7] göre yapılmıştır. Tasarımda Emniyet
Gerilmeleri Yöntemi kullanılmıştır [17]. Yapıların tasarımında esas alınan malzeme ve deprem karakteristikleri Tablo 2'de verilmiştir. Analizlerde, arakatta kompozit dőşeme 
oluşturulacağı düşünülerek rijit diyafram kabulü yapılmıştır.

Tablo 2. Tasarımda esas alınan karakteristikler

\begin{tabular}{|c|c|c|c|}
\hline $\begin{array}{r}\text { Mal } \\
\text { Karakte }\end{array}$ & $\begin{array}{l}\text { eme } \\
\text { istikleri }\end{array}$ & $\begin{array}{c}\text { Deprem } \\
\text { Karakteristikleri }\end{array}$ & \\
\hline Çelik Türü & Fe 37 & $\begin{array}{l}\text { Yapı Önem } \\
\text { Katsayısı (I) }\end{array}$ & 1 \\
\hline $\begin{array}{l}\text { Akma } \\
\text { Dayanımı }\end{array}$ & $\begin{array}{l}235 \\
\mathrm{~N} / \mathrm{mm}^{2}\end{array}$ & $\begin{array}{l}\text { Etkin Yer İvmesi } \\
\text { Katsayısı }\end{array}$ & 0.40 \\
\hline $\begin{array}{l}\text { Çekme } \\
\text { Dayanımı }\end{array}$ & $\begin{array}{l}363 \\
\mathrm{~N} / \mathrm{mm}^{2}\end{array}$ & Zemin Sinıfi & $\mathrm{Z} 2$ \\
\hline $\begin{array}{l}\text { Elastisite } \\
\text { Modülü }\end{array}$ & $\begin{array}{l}206.2 \\
\mathrm{kN} / \mathrm{mm}^{2}\end{array}$ & $\begin{array}{l}\text { Hareketli Yük } \\
\text { Kat. Kats.(n) }\end{array}$ & 0.30 \\
\hline
\end{tabular}

Kütlelerin, ikinci kat kolonlarının üst ucunda, arakatta ise kütle merkezinde toplandıkları varsayılmıştır. Yapıların tasarımında esas alınan sabit ve hareketli düşey yükler Tablo 3'de verilmiştir. Yapılarda ayrıca taşıyıcı elemanların öz yükleri bulunmaktadır.

Tablo 3. Tasarımda esas alınan düșey yükler

\begin{tabular}{cll}
\hline & Çatı Kaplaması & $0.117 \mathrm{kN} / \mathrm{m}^{2}$ \\
\cline { 2 - 3 } Sabit & Aşıklar & $0.105 \mathrm{kN} / \mathrm{m}^{2}$ \\
\cline { 2 - 3 } Yükler (G) & Cephe Elemanları & $0.117 \mathrm{kN} / \mathrm{m}^{2}$ \\
\cline { 2 - 3 } & Betonarme Döşeme & $1.56 \mathrm{kN} / \mathrm{m}^{2}$ \\
\cline { 2 - 3 } & Döşeme Kirişi & $0.40 \mathrm{kN} / \mathrm{m}^{2}$ \\
\hline Hareketli & Kar Yükü & $0.75 \mathrm{kN} / \mathrm{m}^{2}$ \\
\cline { 2 - 3 } Yükler (Q) & Arakat Yükü & $5.00 \mathrm{kN} / \mathrm{m}^{2}$ \\
\hline
\end{tabular}

Diyagonal tipi, Ters V tipi ve 2 Katta $\mathrm{X}$ tipi çaprazlı perdelerin çapraz tasarımında burkulma boyu eleman boyuna eşit alınmıştır. X tipi çaprazlı perdenin basınca çalışan çaprazlı alternatifinde çaprazların orta noktalarından uygun şekilde birleştirildiği kabul edimiş ve burkulma boyları eleman boyunun yarısı alınmıştır [10]. Sadece çekmeye çalışan $\mathrm{X}$ tipi çaprazlı perdede, çaprazlar L tipi profiller ile oluşturulmuş ve orta noktalarından birleşim yapılmayacağı kabul edilerek burkulma boyu eleman boyuna eşit alınmıştır. Böylece eğilme burkulması bakımından yüksek narinlikli, basınç yükü taşımayan çaprazlar elde edilmiştir. Bu çaprazların tasarımı, arttırılmış deprem yükleri altında oluşan çekme kuvvetlerine göre yapılmıştır [7].

Yapılarda çerçeve kirişleri ve kolonlar için IPE, çaprazlar için daire kesitli boru veya L (korniyer), çapraz sistemi kirişleri için kare kesitli boru profiler kullanılmıştır.

Kısa doğrultudaki çerçeve sistemin özellikleri tüm yapılarda aynı olduğu için, çerçeve kirişleri ve kolonları tüm yapılarda aynı boyutta elde edilmiştir. Kısa doğrultudaki süneklik düzeyinin değișimi bu elemanların boyutlarını değiştirmemiştir. $\mathrm{Bu}$ nedenle tasarım sonucunda yapılarda sadece çapraz tipleri ve boyutları farklılık göstermiştir.

Kısa doğrultudaki $(\mathrm{X})$ çerçeve sistemin hakim periyodu $\mathrm{T}_{1 \mathrm{x}}=0.64 \mathrm{~s}$ ve taban kesme kuvveti, süneklik düzeyi yüksek tasarımda $\mathrm{V}_{\mathrm{Tx}}=765 \mathrm{kN}$, süneklik düzeyi normal tasarımda $\mathrm{V}_{\mathrm{Tx}}=1124 \mathrm{kN}$ olarak elde edilmiştir. Yapıların uzun doğrultularına ait hakim periyotlar $\left(\mathrm{T}_{1 \mathrm{y}}\right)$ ve taban kesme kuvvetleri (Vt) Tablo 4'de verilmiștir. Yapıların tasarımında rüzgar yükleri de gözönüne alınmış ancak etkili olmamıştır [18].

Tablo 4. Yapıların uzun doğrultu periyotları ve deprem kuvvetleri

\begin{tabular}{lcc}
\hline Yapı adı (Kodu) & $\begin{array}{c}\text { Periyot } \\
\left(\mathrm{T}_{1 \mathrm{y}}\right) \\
(\mathrm{s})\end{array}$ & $\begin{array}{c}\text { Taban Kesme } \\
\text { Kuvveti }(\mathrm{Vt}) \\
(\mathrm{kN})\end{array}$ \\
\hline Yapı-1 (DÇ-SDY) & 0.271 & 1260 \\
\hline Yapı-2 (DÇ-SDN) & 0.250 & 1575 \\
\hline Yapı-3 (TVÇ-SDY) & 0.291 & 1260 \\
\hline Yapı-4 (TVÇ-SDN) & 0.262 & 1575 \\
\hline Yapı-5 (2KXÇ-SDY) & 0.286 & 1260 \\
\hline Yapı-6 (2KXÇ-SDN) & 0.255 & 1575 \\
\hline Yapı-7 (XÇ-SDY) & 0.283 & 1260 \\
\hline Yapı-8 (XÇ-SDN) & 0.277 & 1575 \\
\hline Yapı-9 (ÇÇC-SDN) & 0.279 & 1575 \\
\hline
\end{tabular}


Tasarım sonucunda tüm kolonlar için IPE 500 profili, kirişler için IPE 400 profili, uzun doğrultudaki çapraz sistemi kirişleri için Kutu 140.140.8 profili kullanılmıştır. Yapı-1'e ait tasarım sonuçları özeti örnek olarak Tablo 5'de verilmiştir. Her bir yapıda uzun doğrultudaki çaprazlı perdeleri oluşturan çapraz elemanları için elde edilen profiller Tablo 6'da verilmiştir. Her bir yapının tasarımına ait daha detaylı bilgi [19]'da bulunabilir.

Tablo 5. Yapı-1'e ait tasarım sonuçları özeti

\begin{tabular}{|c|c|c|c|c|c|c|}
\hline \multicolumn{2}{|l|}{ Tasarım Parametresi } & $\begin{array}{l}\text { Çerçeve } \\
\text { Kolonu } \\
\text { IPE 500 }\end{array}$ & $\begin{array}{l}\text { Çerçeve } \\
\text { Kirişi } \\
\text { IPE } 450\end{array}$ & $\begin{array}{l}\text { Alt } \\
\text { Çaprazlar } \\
\text { Boru } \\
219.1 * 5\end{array}$ & $\begin{array}{c}\text { Üst } \\
\text { Çaprazlar } \\
\text { Boru } \\
193.7 * 4.5\end{array}$ & $\begin{array}{c}\text { Çaprazlı } \\
\text { Perde } \\
\text { Kirişleri } \\
\text { Kutu } \\
140 * 140 * 8\end{array}$ \\
\hline \multicolumn{2}{|l|}{ Eleman Boyu (m) } & $4.0 \mathrm{~m}$ & $12.23 \mathrm{~m}$ & $7.21 \mathrm{~m}$ & $7.21 \mathrm{~m}$ & $6.0 \mathrm{~m}$ \\
\hline \multirow{2}{*}{ Enkesit Narinlik Oranı/Sınır Nar. Oranı } & $\mathrm{b}_{\mathrm{f}} / 2 \mathrm{t}_{\mathrm{f}}$ & $6.25 / 8.88$ & $6.50 / 8.88$ & ----- & ----- & ----- \\
\hline & $\mathrm{h} / \mathrm{t}_{\mathrm{w}}-\mathrm{D} / \mathrm{t}$ & $45.88 / 89.33$ & $44.76 / 94.7$ & $8.74 / 70.8$ & $43.04 / 70.8$ & $15.35 / 35.5$ \\
\hline \multicolumn{2}{|c|}{ Maksimum Eleman Narinliği/Sınır Narinlik } & $93 / 250$ & $75 / 250$ & $95 / 118$ & $104 / 118$ & $113 / 118$ \\
\hline \multirow{2}{*}{ Mak.Gör.Öt./Sınır Öt. Oranı } & Üst Kat $\quad \mathrm{G}+\mathrm{Q}+\mathrm{E}_{\mathrm{x}}+0.3 \mathrm{E}_{\mathrm{y}}$ & $0.02 / 0.02$ & ---- & ---- & ---- & ---- \\
\hline & Alt Kat $\quad \mathrm{G}+\mathrm{Q}+\mathrm{E}_{\mathrm{x}}+0.3 \mathrm{E}_{\mathrm{y}}$ & $0.014 / 0.02$ & ----- & ----- & ----- & ----- \\
\hline \multicolumn{2}{|c|}{ Maksimum Sehim/Sınır Sehim (m) } & ---- & $0.044 / 0.08$ & --- & ---- & ---- \\
\hline Mak.Normal Ger.Oranı/Sınır Ger. Oranı & $\mathrm{G}+\mathrm{Q}-\mathrm{E}$ & $0.85 / 1.33$ & $1.15 / 1.33$ & $1.20 / 1.33$ & $0.56 / 1.33$ & $0.16 / 1.33$ \\
\hline Mak. Kayma Ger. Oranı/Sınır Ger.Oranı & r.Oranı $\quad G+Q-E_{x}-0.3 E_{y}$ & $0.20 / 1.33$ & $0.32 / 1.33$ & ---- & ----- & ---- \\
\hline
\end{tabular}

İncelenen yapılardaki çapraz eleman ağırlıklarının $23 \mathrm{kN}$ ile $30 \mathrm{kN}$ arasında değiştiği görülmüştür. En fazla çapraz ağırlığı süneklik düzeyi normal olarak tasarlanan Diyagonal tipi çaprazlı perde sistemde, en düşük çapraz ağırlığı ise Sadece Çekmeye Çalışan X tipi çaprazlı perde sistemde elde edilmiştir.

Tablo 6. Yapıların uzun doğrultu çapraz elemanları

\begin{tabular}{lll}
\hline Yapı Adı & Alt Çapraz & Üst Çapraz \\
\hline Yapı-1 & Boru 219.1*5 & Boru 193.7*4.5 \\
\hline Yapı-2 & Boru 244.5*5.4 & Boru 193.7*4.5 \\
\hline Yapı-3 & Boru 168.3*4 & Boru 139.7*4 \\
\hline Yapı-4 & Boru 193.7*4.5 & Boru 139.7*4 \\
\hline Yapı-5 & Boru 168.3*4 & Boru 139.7*4 \\
\hline Yapı-6 & Boru 193.7*4.5 & Boru 139.7*4 \\
\hline Yapı-7 & Boru 127*4 & Boru 101.6*3.6 \\
\hline Yapı-8 & Boru 133*4 & Boru 101.6*3.6 \\
\hline Yapı-9 & L 130*130*16 & L 80*80*8 \\
\hline
\end{tabular}

2.2. Yapıların uzun doğrultu deprem performans seviyelerinin belirlenmesi

Yapıların performans değerlendirmeleri ASCE 41-13 [10]'de verilen esaslar çerçevesinde Doğrusal Olmayan Statik Yöntem ile yapılmıştır. Çalışmada çaprazlı perde tipinin deprem performansına etkisi incelendiği için sadece uzun doğrultuya ait performans değerlendirmeleri sunulmuştur. Kisa doğrultu ile ilgili detaylı bilgi [19]'da bulunabilir.

Deprem etkisinde kolonlar, kirişler ve çaprazlar eksenel yüklü eleman olarak gözönüne alınmış ve elemanların Normal Kuvvet-Boy Değişimi bağıntıları kullanılmıştır. Sistemdeki ikincil elemanlar (arakat kirişleri, kolonları, döşeme kirişleri, aşıklar, çatı stabiliteleri) ve birleşimler performans 
değerlendirmesinde gözönüne alınmamıştır.

Taşıyıcı sistemlerde $(\mathrm{G}+0.3 \mathrm{Q})$ düşey yükleri altında monoton artan yatay yükler için doğrusal olmayan analizler yapılmıştır. $\mathrm{Bu}$ analizlerde SAP2000 Yapisal Analiz Programı'ndan yararlanılmıştır [20]. Analizde deprem etkilerini temsil eden yatay yük olarak 1 . mod şekli ile uyumlu yükler kullanılmıştır. Tepe yerdeğiştirmesi olarak, kolon üst ucunun yatay yerdeğiştirmesi $\left(\mathrm{u}_{\mathrm{Ty}}\right)$, esas alınmıştır. Sistemlerin doğrusal olmayan analizlerinde;

- Elemanların iç kuvvetşekildeğiştirme bağıntılarının doğru parçaları ile idealleştirilebileceği kabul edilmiştir.

- Birleşim araçlarının taşıma kapasitelerinin, birleştirilen elemanlardan daha fazla olduğu, bu nedenle birleşimlerin elastik davrandığı kabul edilmiştir.

Çalışmada incelenen yapıların kullanım amacı endüstri yapısı olduğu için önem katsayısı $\mathrm{I}=1.00$ olmaktadır. $\mathrm{Bu}$ nedenle yapiların performans değerlendirilmesinde Türkiye Deprem
Yönetmeliği'nde öngörülen, 50 yılda aşılma olasılığı \% 10 olan tasarım depremi esas alınmıştır [7].

Taşıyıcı sistem elemanlarına ait iç kuvvet- şekildeğiştirme bağıntıları ve performans seviyelerine ait sinır şekildeğiştirmeler eleman enkesit özelliklerine ve eğilme burkulması narinliklerine bağlı olarak belirlenmiştir $[10,21,22]$. Çapraz sistemi kolonları ve kirișleri ASCE 41-13'e göre çekme kuvveti altında șekildeğiștirme kontrollü, basınç kuvveti altında kuvvet kontrollü olarak gözönüne alınmaktadır [10]. Çapraz elemanlar ise çekme ve basınç kuvveti altında șekildeğiștirme kontrollü olarak gözönüne alınmaktadır. Kolon ve çapraz kirişi için elde edilen normal kuvvet-boy değişimi bağıntıları Şekil 3'de gösterilmiştir. Kolon ve çapraz kirişi için tüm yapılarda bu bağıntılar kullanılmıștır. Çapraz elemanları için ise her bir yapıdaki çapraz özelliklerine göre belirlenen bağıntılar kullanılmıștır. Șekil 4'de Yapı-1'e ait alt çapraz için elde edilen bağıntı örnek olarak verilmiştir.

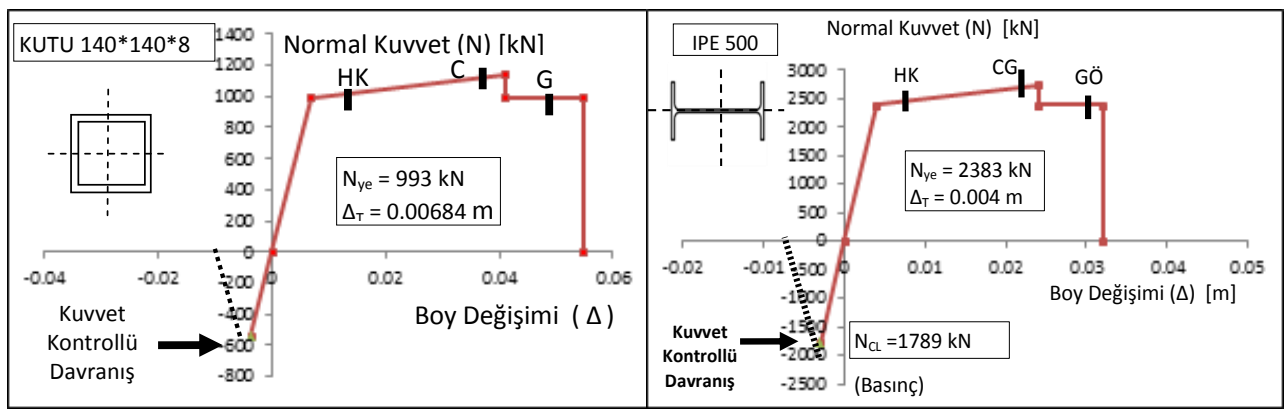

Şekil 3. Çapraz sistemi kolonu ve kirişi için normal kuvvet-boy değișimi bağıntıları. 


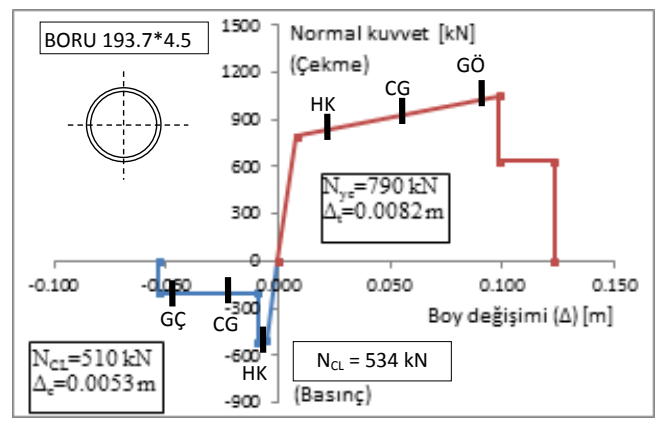

Şekil 4 . Çapraz elemanı için normal kuvvet - boy değişimi bağıntısı (Yapı-1 alt çapraz)

Şekil 3 ve 4'de verilen grafiklerde, $\mathrm{N}_{\mathrm{ye}}$ elemanın çekme kuvveti altında akma kuvvetini, $\Delta_{\mathrm{T}}, \mathrm{N}_{\mathrm{ye}}$ kuvvetine maruz elemandaki uzamayı, $\mathrm{N}_{\mathrm{CL}}$ elemanın basınç kuvveti taşıma kapasitesini, $\Delta_{\mathrm{C}}$, $\mathrm{N}_{\mathrm{CL}}$ kuvvetine maruz elamandaki kısalmayı göstermektedir. Bağıntılar üzerinde belirtilen HK Hemen Kullanım performans seviyesine, CG Can Güvenliği performans seviyesine, GÇ Göçme Önleme performans seviyesine ait şekildeğiştirme (uzama/kısalma) sınırlarını göstermektedir [10]. ASCE 41-13 [10]'de Hemen Kullanım performans seviyesi ile Can Güvenliği performans seviyesinin arasında kalan şekildeğiştirme bölgesi Arttırılmış Güvenlik yapısal performans bölgesi, Can Güvenliği performans seviyesi ile Göçme Önleme performans seviyesinin arasında kalan şekildeğiștirme bölgesi Azaltılmış Güvenlik yapısal performans bölgesi olarak tanımlanmaktadır. Ayrıca daha ayrintılı performans değerlendirmeleri yapabilmek amacıyla temel performans sevilerinin (HK, CG, GÖ) aralarında Hasar Kontrol performans seviyesi ve Sinırlı Güvenlik performans seviyesi olmak üzere iki performans seviyesi daha tanımlanmıştır. $\mathrm{Bu}$ performans seviyelerinin şekil değiştirme sınırları, en yakın performans sevilerine ait sinırların ortası alınarak belirlenmektedir. ASCE 41-13'de tanimlanan yapisal performans seviyeleri ve bölgeleri tipik bir kapasite eğrisi üzerinde şematik olarak Şekil 5’de gösterilmiştir. Türkiye Deprem Yönetmeliğinde çelik yapılar ile ilgili Can Güvenliği performans kriterleri bulunmadığı için ASCE 41-13'de tanımlanan kriterlerin geçerli olduğu kabul edilmiştir. Her bir yapı için doğrusal olmayan statik analiz ile yapıların kapasite eğrileri elde edilmiştir (Şekil 6).



Şekil 5. Tipik bir kapasite eğrisi üzerinde performans seviyeleri ve bölgeleri. 


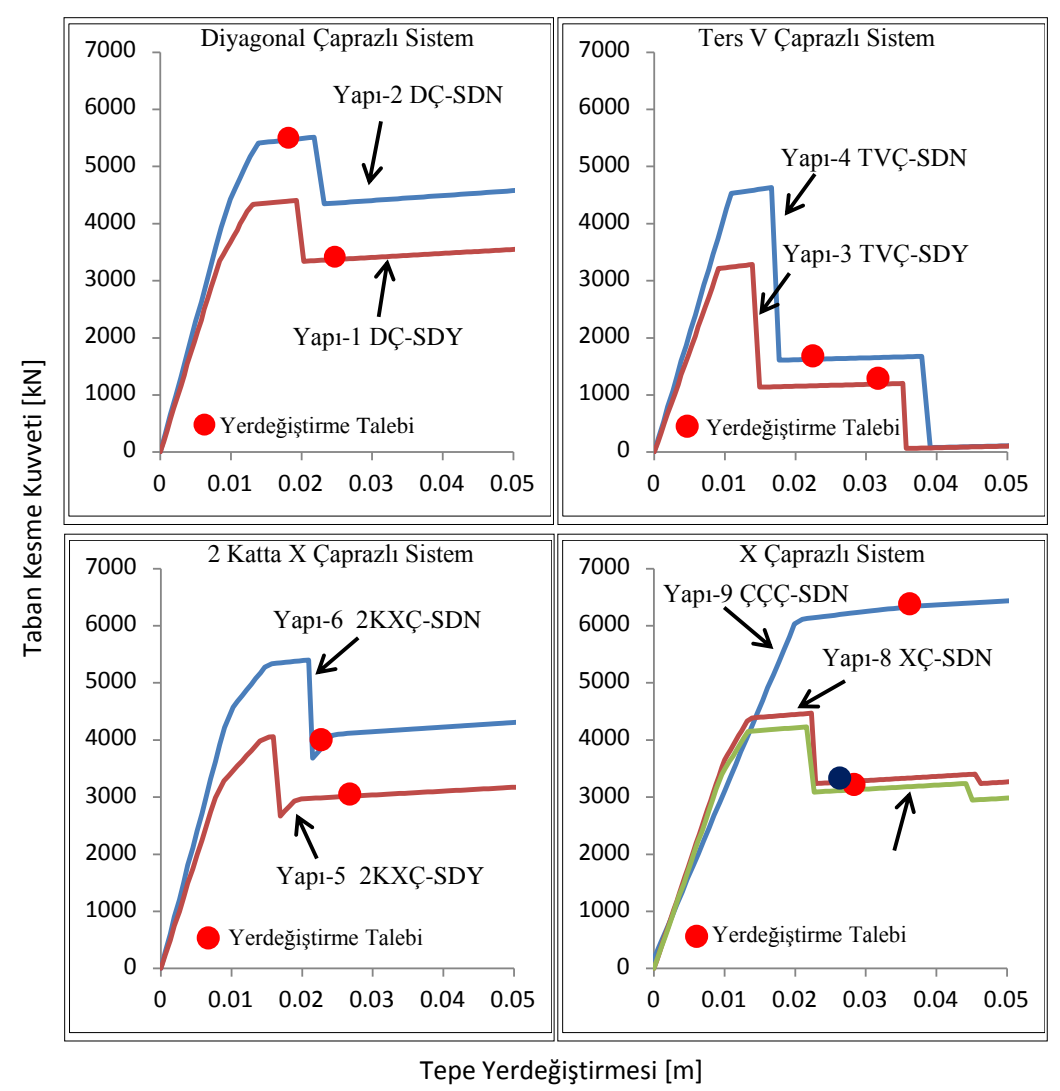

Şekil 6. Yapıların kapasite eğrileri ve gözönüne alının deprem için yerdeğiștirme talepleri

Kapasite eğrileri üzerinde ASCE 41-13 [10]'e göre gerekli idealleştirmeler yapılarak yerdeğiştirme katsayıları yöntemi ile gözönüne alınan deprem tehlike seviyesi için yerdeğiştirme talepleri belirlenmiştir. Bu yönteme göre hedef yerdeğiștirme $\left(u_{T}\right)(1)$ bağıntısı ile elde edilmektedir.

$\mathrm{u}_{\mathrm{T}}=\mathrm{C}_{0} \mathrm{C}_{1} \mathrm{C}_{2} \mathrm{~S}_{\mathrm{a}} \frac{\mathrm{T}_{\mathrm{s}}^{2}}{4 \pi^{2}}$

Burada $\mathrm{C}_{0}$ eşdeğer tek serbestlik dereceli sistemin spektral yerdeğitirmesini, çok serbestlik dereceli bir sistemin tepe yerdeğiştirmesi ile ilișkilendiren katsayıyı, $C_{1}$ doğrusal-elastik davranış için hesaplanmış yerdeğiştirmeler ile beklenen maksimum elastik olmayan yerdeğiștirmeleri ilișkilendiren katsayıyı, $\quad C_{2}$ tekrarlı yükler altında histeretik yerdeğiştirme davranışı üzerinde rijitlik azalması ve dayanım kaybı etkisini temsil eden değişiklik katsayısını, $S_{a}$ performans değerlendirmesinin yapılacağı deprem için yapının birinci doğal titreşim periyoduna karşllık gelen spektral ivmeyi, $\quad T_{e} \quad$ kapasite eğrisinin idealleştirilmesi ile elde edilen başlangıç rijitliğine karşı gelen efektif periyodu göstermektedir.

Her bir yapı için elde edilen hedef yerdeğiștirme değerleri, buna karşsllk gelen taban kesme kuvvetleri ve ilgili parametreler Tablo 7'de verilmiștir. 
Tablo 7. Yapılara ait yerdeğiştirme talepleri, taban kesme kuvvetleri ve ilgili parametreler

\begin{tabular}{ccccccc}
\hline Yapı adı & $\mathrm{C}_{0}$ & $\mathrm{C}_{1}$ & $\mathrm{C}_{2}$ & $\begin{array}{c}\text { Efektif Periyot } \\
\left(\mathrm{T}_{\mathrm{e}}\right)(\mathrm{s})\end{array}$ & $\begin{array}{c}\text { Hedef yerd. } \\
\mathrm{U}_{\mathrm{T}}(\mathrm{m})\end{array}$ & $\begin{array}{c}\text { Taban Kesme } \\
\text { Kuvveti }(\mathrm{Vt})(\mathrm{kN})\end{array}$ \\
\hline Yapı-1 & 1.2 & 1.105 & 1.018 & 0.278 & 0.0259 & 3380 \\
\hline Yapı-2 & 1.2 & 1.018 & 1.008 & 0.251 & 0.0204 & 5695 \\
\hline Yapı-3 & 1.2 & 1.157 & 1.044 & 0.293 & 0.0305 & 1187 \\
\hline Yapı-4 & 1.2 & 1.104 & 1.015 & 0.263 & 0.0231 & 1627 \\
\hline Yapı-5 & 1.2 & 1.105 & 1.020 & 0.296 & 0.0298 & 3035 \\
\hline Yapı-6 & 1.2 & 1.074 & 1.008 & 0.263 & 0.0224 & 3810 \\
\hline Yapı-7 & 1.2 & 1.075 & 1.020 & 0.286 & 0.0276 & 3124 \\
\hline Yapı-8 & 1.2 & 1.100 & 1.017 & 0.280 & 0.0262 & 3261 \\
\hline Yapı-9 & 1.2 & 1.018 & 1.000 & 0.350 & 0.0373 & 6344 \\
\hline
\end{tabular}

Yapıların kapasite eğrileri karşılaştırıldığında (Şekil6);

- Hedef yerdeğiştirme değerine ulaşmış yapılarda en büyük yatay yük taşıma kapasitesi süneklik düzeyi normal olarak tasarlanan Sadece Çekmeye Çalışan X tipi çaprazlı perde sistemde elde edilmiştir. En düşük yatay yük taşıma kapasitesi ise süneklik düzeyi yüksek olarak tasarlanan Ters V tipi çaprazlı perde sistemde elde edilmiştir.

- Basınç çaprazı bulunan tüm yapılarda çaprazlarının burkulması nedeniyle dayanım azalmaları oluşmuştur. Ancak Ters V tipi çaprazlı perde sistemde diğerlerine göre çok daha büyük dayanım azalması görülmüștür. Bunun nedeni, Ters V tipi çaprazlı sistemde basınç çaprazları burkulduktan sonra çekme çubuğundaki kuvvetin dengelenememesidir. 2 katta X tipi çaprazlı sistemde üst kat çaprazları sayesinde, diğer sistemlerde ise kolonlar sayesinde, burkulma sonrası çekme çubuklarındaki kuvvetler dengelenebilmekte ve sistemdeki dayanım azalmaları basınç çubuklarının kapasiteleri kadar olmaktadır.
- Ters V tipi çaprazlı sistemdeki ani ve büyük dayanım azalmaları, ASCE 41-13 [10]'e göre Doğrusal olmayan dinamik yöntem kullanımını gerektirecek mertebede olmuştur. Ancak bu çalışmada diğer yapılarla karşılaştırabilmek amacıyla statik analiz sonuçları esas alınmıştır.

- Sadece çekmeye çalışan X tipi çaprazlı sistemde yanal rijitlik diğer sistemlere göre daha düşük elde edilmiş, ancak basınç çaprazı bulunmadığı için kapasite eğrisinde dayanım azalması oluşmamıștır.

Yapılar, tepe yerdeğiştirmeleri hedef yerdeğiștirme değerine ulaşana kadar itilmiş ve elemanlarda oluşan plastik boy değișimleri belirlenmiștir. Bunlar ASCE 41-13'de verilen sınır değerler ile karşılaştırılarak taşıyıcı sistemlerin temel performans seviyeleri/bölgeleri elde edilmiştir. Her bir yapıda çekme veya basınç altında oluşan plastikleşmeler örnek olarak bir aks için Tablo 8'de gösterilmiştir. 
K.Türker vd. / Tipik Bir Çelik Endüstri Yapısında Çaprazlı Perde Tipinin Deprem Performansına Etkisi

Tablo 8. Yapılardaki hasar (plastikleşme) dağılımları ve en elverişsiz hasar bölgeleri

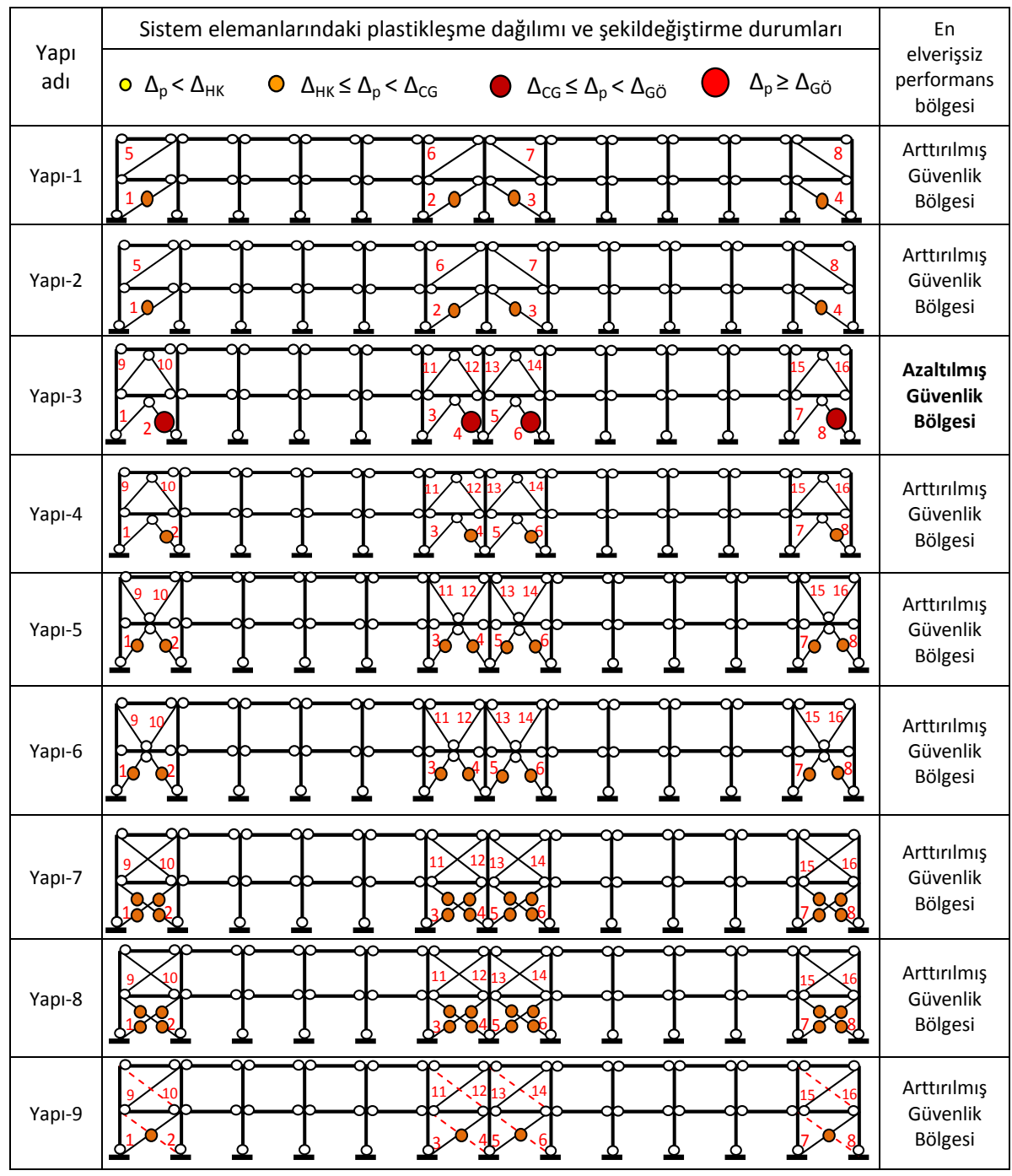

Plastik boy değişimleri performans bölgelerine göre ölçeklenmiş daireler ile belirtilmiştir (Tablo 8).

Yapılarin temel performans seviyeleri ve hasar dağılımları karşılaştırıldığında (Tablo 8);

- Süneklik düzeyi yüksek olarak tasarlanan Ters V tipi çaprazlı sistemin performans seviyesi Azaltılmış Güvenlik Bölgesi olarak elde edilmiştir. Diğer tüm yapıların performansı Arttırılmış Güvenlik Bölgesinde elde edilmiștir.
- Ters V tipi çaprazlı sitemlerde çekme çubuklarında plastikleșme olmazken, diğer sistemlerde çekme çubuklarının da plastikleștiği görülmektedir.

- Tüm yapılarda sadece alt çaprazlarda plastikleşmeler olmuş, üst çaprazlar çekme veya basınç altında elastik davranmıştır. Bunun sebebi, üst çaprazların tasarımında eğilme burkulması narinliklerinin gerilmeye göre daha etkin olmasıdır. 
Temel performans seviyeleri çok geniş şekildeğiştirme aralıklarını içermektedir. $\mathrm{Bu}$ nedenle yapıların performans bölgeleri aynı olmasına rağmen elemanlardaki hasar düzeyleri önemli farklılıklar gösterebilmektedir. Daha ayrıntılı bir performans değerlendirmesi için ASCE 41-13 [10] 'deki ara performans seviyeleri de gözönüne alınarak yapıların performansları belirlenmiş ve Şekil 7'de karşılaştırılmıştır.

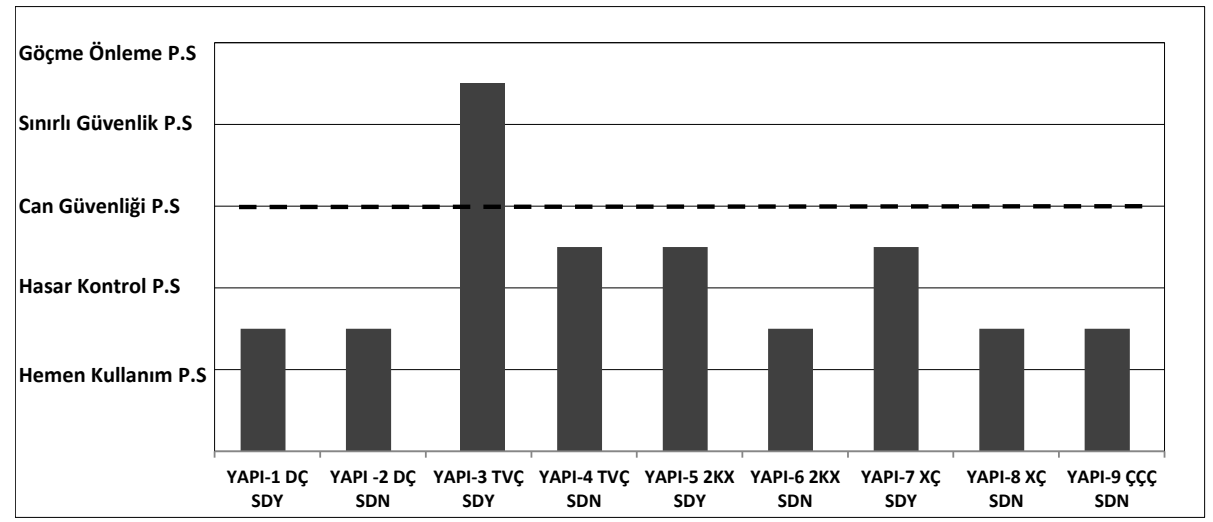

Şekil 7. Yapıların performans seviyelerinin karşılaştırılması.

Sistemlerin detaylı performans seviyeleri karşılaştırıldığında (Şekil 7);

- Süneklik düzeyi yüksek olarak tasarlanan Ters V tipi çaprazların kullanıldığı sistemde ASCE 41-13 [10]'e göre Can Güvenliği performans seviyesinin sağlanamadığı, diğer tüm çapraz tiplerinde ise sağlandığı belirlenmiştir.

- En iyi performans seviyesi, "Hemen Kullanım P.S ile Hasar Kontrol P.S arasındaki bölge " olarak elde edilmiştir. En kötü performans seviyesi ise "Sinirl Güvenlik P.S ile Göçme Önleme P.S arasındaki bölge" olarak elde edilmiştir.

- Süneklik düzeyininin yüksek yerine normal olması Ters V tipi çaprazlı perdeli sistemde, 2 Katta X tipi çaprazlı sistemde ve $\mathrm{X}$ tipi çaprazlı sistemde performans seviyesini iyileştirmiştir.

- Aynı miktarda ve aynı kesitlerde eleman kullanılmasına rağmen 2 Katta $X$ tipi çapraz perdeli sistemin, Ters $\mathrm{V}$ tipi çapraz perdeli sisteme göre deprem performansı bakımından çok daha iyi sonuçlar verdiği görülmüştür. Bu durum basınç çubuklarının burkulması sonrasında 2 Katta X tipi çaprazda çekme çubuklarının dengelenebilmesi sayesinde olmuştur.

\section{Sonuçlar}

Çalışmada, Türkiye Deprem Yönetmeliği 2007 [7]'ye göre tasarlanan çelik endüstri yapılarında farklı çaprazlı perde alternatiflerinin deprem performansları değerlendirilmiștir. İncelemeler iki katlı tipik endüstri yapıları üzeride yapılmıştır. Yapılar bir doğrultuda çerçeve sistemlerden, diğer doğrultuda ise merkezi çaprazlı perde sistemlerden oluşturulmuş̧tur. Çalışmada diyagonal tipi, ters- $\mathrm{V}$ tipi, $\mathrm{X}$ tipi, ve iki katta-X tipi çaprazlı perde olmak üzere 4 farklı merkezi çaprazlı perde tipi incelenmiştir. Herbir çaprazlı perde tipi süneklik düzeyi normal ve yüksek olarak ayrı ayrı tasarlanmıştır. Ayrıca yüksek narinlikte elemanların kullanıldığı sadece çekmeye çalışan X tipi çaprazlı perde tipi de incelenmiştir. Performans değerlendirmeleri ASCE/SEI 41-13 [10] çerçevesinde, 
D oğrusal Olmayan Statik Yöntem ile yapilmıştır. Çalışmada elde edilen sonuçlar aşağıda özetlenmiştir;

- Süneklik düzeyi normal olarak tasarlanan tüm çaprazlı sistemler ASCE 41-13'de öngörülen "Can Güvenliği" performans seviyesini sağlamıştır. Buna göre Türkiye Deprem Yönetmeliğinde öngörülen Can güvenliği kriterinin sağlandığı söylenebilmektedir. Ancak süneklik düzeyi yüksek olarak tasarlanan Ters V tipi çaprazlı perdede öngörülen performans sağlanamamıştır.

- CCapraz tipleri arasında en iyi deprem performansları Diyagonal tip, 2 Katta $X$ tipi, $\mathrm{X}$ tipi ve Sadece Çekmeye Çalışan X tipi çaprazlı sistemlerde elde edilmiştir.

- Süneklik düzeyinin değişimi (normal veya yüksek) tasarımda genel olarak eleman boyutlarını değiştirmiş bu da eleman hasar düzeyini etkilemiștir. Bu değişim Diyagonal tip dışındaki tüm çaprazlarda performans düzeyini değiștirecek mertebede etkili olmuștur. Buna göre az katlı çelik endüstri yapılarında, tasarımların süneklik düzeyi normal olarak yapılmasının deprem performansı bakımından daha uygun olacağı söylenebilmektedir.

- Aynı miktarda ve ayn kesitlerde eleman kullanılmasına rağmen 2 Katta $X$ tipi çaprazlı perde sistemin, aynı süneklik düzeyine sahip Ters $\mathrm{V}$ tipi çaprazlı perde sisteme göre deprem performansı bakımından çok daha iyi sonuçlar verdiği görülmüştür. Bunun nedeni, Ters $\mathrm{V}$ tipi çapraz sisteminde basınç çaprazları burkulduktan sonra çekme çubuğundaki kuvvetin dengelenememesi, 2 Katta X tipi Çapraz sistemde ise üst kat çaprazlarının söz konusu dengeyi sağlayabilmesidir. Buna göre iki katlı yapılarda ters V tipi çaprazlı perde yerine, 2 Katta $X$ tipi perde kullanmanın daha uygun olacağı söylenebilmektedir. Aksi halde daha güçlü kirişler kullanılması, kolon- kiriş birleşimlerinin moment aktaracak şekilde yapılması vb. önlemler alınması gerekmektedir.
- Ters V tipi çaprazlı sistemlerde çaprazların burkulması ile oluşan büyük ve ani dayanım kaybı ASCE 41-13'e göre statik yöntemin kullanım sınırını aşacak mertebede olmuştur. Diğer tüm çapraz tiplerinde ise statik yöntem yeterli olmuştur. Buna göre Ters V tipi çapraz kullanılması durumunda daha ayrintılı olan dinamik yöntemlerin tercih edilmesi uygun olacaktır.

- Türkiye Deprem yönetmeliğine göre en çok iki katlı yapılarda izin verilen Sadece Çekmeye Çalışan X tipi çaprazlı sistem, kullanılan malzeme ağırlığı bakımından ekonomik sonuç verdiği gibi, performans düzeyi bakımından da en iyi çapraz tipleri arasında yer almıştır.

\section{Kaynakça}

[1] G. Altay ve M. S. Güneyisi. 2005. Türkiye'de yapısal çelik sektörü ve yeni gelişimler. Antalya Yöresinin İnşaat Mühendisliği Sorunları Kongresi, Antalya, 22-24 Eylül.

[2] B. Davison, G. Owens. 2005, Steel Designers Manual 7th edition. G. Raven, A. Pottage. Single Storey Buildings. Wiley-Blackwll. 1370p.

[3] L. Martin ve J. Purkiss. 2008. Structural design of steelwork to EN 1993 and EN 1994, 3th edition, United Kindom, Elsevier Ltd. 487p.

[4] Structural Engineers Association of California (SEOAC). 1995. Vision 2000: Performance Based Seismic Engineering of Buildings. Sacramento CA. USA.

[5] Federal Emergency Management Agency (FEMA). 2000. FEMA 356: NEHRP Commentary on the Guidelines for the Seismic Rehabilitation of Buildings. Washington, DC., USA.

[6] J. P. Moehle. 2003. A framework for performance-based earthquake engineering. Tenth U.S.-Japan Workshop on Improvement of Building Seismic Design and 
Construction Practices, Redwood City, CA. USA.

[7] Bayındırlık ve İskan Bakanlı̆̆ı. 2007. Deprem Bölgelerinde Yaplacak Binalar Hakkında Yönetmelik (DBYBHY). Bakanlıklar, Ankara.

[8] Kandilli Rasathanesi ve Deprem Araştırma Enstitüsü (KOERI). 2008. İstanbul Yüksek Binalar Deprem Yönetmeliği. Versiyon 3, İstanbul.

[9] American Society of Civil Engineers (ASCE). 2007. ASCE/SEI41-06: Seismic Rehabilitation of Existing Buildings. Virginia, USA.

[10] American Society of Civil Engineers (ASCE). 2013. ASCE/SEI41-13: Seismic Evaluation and Retrofit of Existing Buildings. Virginia, USA.

[11] Comité Européen de Normalisation (CEN). 2003. Eurocode 8 : Design of Structures for Earthquake Resistance-Part 3: Assessment and Retrofitting of Buildings. Bruxelles, Belgium.

[12] Cevre ve Șehircilik Bakanlığı. 2016. Türkiye Bina Deprem Yönetmeliği (Taslak). Bakanlıklar, Ankara.

[13] A. Amini, M. Majd ve M. Hosseini. 2012. A Study on the Effect of Bracing Arrangement in the Seismic Behavior Buildings with Various Concentric Bracings by Nonlinear Static and Dynamic Analyses. Fifthteenth World Conference on Earthquake engineering, Lisbon, Portugal.

[14] M. Bruneau, C. Uang ve R. Sabelli. 2011. Ductile Design of Steel Structures. 2nd Edition, Mc. Graw Hill, USA, 369p.

[15] R. Barros, M. Braz-César, H. Naderpour ve S. Khatami. 2013. Comparative Review of the Performance Based Design of Building Structures Using Static Non-Linear Analysis Part A: Steel Braced Frames. Journal of Rehabilitation in Civil Engineering,
Cilt 1, No. 2, pp. 24-39,

[16] D. Rai ve S. Goel. 2003. Seismic evaluation and upgrading of chevron braced frames. Journal of Constructional Steel Research Cilt 59, p. 971-994. DOI:10.1016/S0143974X(03)00006-3

[17] Türk Standartları Enstitüsü (TSE). 1980. TS648: Çelik Yapıların Hesap ve Yapım Kuralları. Ankara.

[18] Türk Standartları Enstitüsü (TSE). 1997. TS498: Yapı Elemanlarının Boyutlandırılmasında Alınacak Yüklerin Hesap Değerleri. Ankara.

[19] İ. Lekesiz. 2016. Tipik Bir Çelik Endüstri Yapısında Caprazlı Perde Tipinin Deprem Performansına Etkisinin İncelenmesi, Balıkesir Üniversitesi, Fen Bilimleri Enstitüsü Yükek Lisans Tezi, 141s, Balıkesir.

[20] Computers and Structures (CSI). 2008. SAP2000.V.8: Structural Analysis Programs- User's Manual, Berkeley California, USA.

[21] American Institute of Steel Construction (AISC). 1999. Load and Resistance Factor Design Specification for Structural Steel Buildings. llinois- USA.

[22] American Institute of Steel Construction (AISC). 2010. ANSI/AISC360-10: Specification for Stuructural Steel Buildings. Inc. Illinois- USA. 